\title{
GRUPO PADRE LUIZ GONZAGA - BRAGANÇA-PA: ARQUIVOS, MÉTODO E FONTES DA HISTÓRIA DA EDUCAÇÃO DA AMAZÔNIA, NO SÉCULO XX ${ }^{1}$
}

\author{
Maria José Aviz do Rosário \\ mrosario@ufpa.br \\ Clarice Nascimento de Melo \\ mnclarice@gmail.com \\ Universidade Federal do Pará - UFPA
}

\section{RESUMO}

O trabalho objetiva apresentar análise das primeiras fontes históricas sobre o Grupo Escolar Padre Luiz Gonzaga, de Bragança - PA. Pautou - se em dois propósitos, recuperação e disponibilização da história e memória dessa instituição escolar, de formação do povo bragantino, no Século XX e contribuição ao registro de fontes históricas das instituições escolares da Região Amazônica. A metodologia constituiu-se do levantamento e análise de fontes históricas documentais, orais e iconográficas. Na análise procurou - se discutir o conceito e a importância de método do trabalho com fontes históricas, articulando o conhecimento mais geral sobre a formação educacional paraense e brasileira, fazendo-se aproximações de como foram forjadas as propostas educacionais no contexto bragantino por meio do grupo. A primeira etapa dedicou-se aos documentos escritos, Projeto Político Pedagógico e cadernetas escolares e a iconografia composta de retratos com os quais pode se compor as primeiras cenas da educação do grupo. Em seguida ouviu-se a segunda diretora, a segunda secretária e as professoras da primeira geração e segunda geração. A análise aponta o grupo como instrumento de articulação da proposta de expansão da educação primária nos anos de 1960, já que sua criação, em 1962, atendia a reivindicação da nova população da cidade, composta de agricultores e pescadores dos campos, das praias e colônias que empurrados para os arrabaldes da cidade, exigiam do poder público, escola para seus filhos. A escola também era tida como modelo pedagógico em que prevaleciam o respeito e a disciplina; o amor à pátria incutido pelo cântico do Hino Nacional; a preocupação em não deixar criança sem estudar, por meio do famoso "jeito"; a influência da igreja católica; pela catequese de responsabilidade da paróquia, cujo ápice era realização da primeira comunhão; a distribuição de merenda escolar, inicialmente proveniente das Cáritas Brasileira e mais tarde por doações de pessoas do bairro e; a indumentária das professoras, blusa branca e saia preta, professoras do Padre Luiz, orgulhosas da profissão'. A análise permite afirmar, os arquivos e fontes, apontam no grupo, vestígios de uma educação que acompanhou as mudanças ocorridas na sociedade brasileira e bragantina, às vezes sem se dar conta, 'passamos do ensino velho (lei 4.024/61) para o ensino novo (lei 5.692/72), sem muitos traumas, foi tudo normal, como mandava a SEDUC' e o retrato de uma das instituições escolares, do Século XX, mais importantes de formação, do povo bragantino, paraense e, por conseguinte, da Amazônia.

Palavras chave: Instituições Escolares; Fontes Históricas; Grupo Escolar Padre Luiz Gonzaga 


\title{
PRIMARY SCHOOL PADRE LUIZ GONZAGA - BRAGANÇA-PA: ARCHIVES, METHOD AND HISTORY OF EDUCATION OF SOURCES FROM AMAZON IN THE TWENTIETH CENTURY
}

\begin{abstract}
The study aims to provide analysis of the first historical sources on the School Group Padre Luiz Gonzaga de Bragança - PA. Guided - in two purposes, recovery and availability of history and memory of this educational institution, training the bragantino people in the twentieth century and contribution to the recording of historical sources of educational institutions in the Amazon region. The methodology consisted of the survey and analysis of documentary historical sources, oral and iconographic. The analysis sought - to discuss the concept and the importance of the work method with historical sources, articulating more general knowledge of Pará and Brazilian educational background, having become approximations of how they were forged educational proposals in bragantino context by group. The first stage was dedicated to documentary material, Political Pedagogical Project and school reports and the iconography made up of portraits with which can - be composed the first scenes of group education. Then there was the second director, the second secretary and the teachers of the first generation and second generation. The analysis shows the group as joint instrument of expansion proposal of primary education in the 1960s, since its creation in 1962, met the claim of the new population of the city, made up of farmers and fishermen fields, beaches and colonies that pushed the outskirts of the city, demanding the government, school for their children. The school was also taken as a pedagogical model that prevailed respect and discipline; love of country instilled by the National Anthem song; the concern not to leave children without studying, through the famous "way"; the influence of the Catholic Church; the responsibility of the parish catechesis, whose summit was carrying out the first communion; the distribution of school lunches, originally from the Brazilian Caritas and later by the neighborhood people and donations; the clothing of the teachers, white blouse and black skirt, teachers of Father Luiz, proud of the profession '. The analysis allows us to affirm, files and fonts, point in the group, traces of an education that accompanied the changes in the Brazilian and bragantina society, sometimes without realizing it, 'we passed the old school (Law 4,024 / 61) for teaching new (Law 5.692 / 72), without much trauma, everything was normal as sent SEDUC 'and the portrait of one of the educational institutions of the twentieth century, most important of training, bragantino people, Pará and therefore the Amazon.

Keywords: School institutions; Historical sources; Primary School Padre Luiz Gonzaga
\end{abstract}

O presente artigo discute os resultados da segunda fase ${ }^{2}$ do projeto de pesquisa, Museu da Educação Amazônico $^{3}$, dedicada ao levantamento, higienização, organização, catalogação, sistematização e digitalização de acervos de instituições escolares paraenses; objetiva apresentar análise das primeiras fontes sobre o Grupo Escolar Padre Luiz Gonzaga, fundado em 1962, localizado em Bragança, nordeste paraense, bem como contribuir para ampliar o debate a respeito do conceito e uso de fontes históricas. 
Em termos de sua estruturação o artigo apresenta os elementos que o compõem, dos quais se evidencia uma breve descrição do problema, que aponta dificuldades de se circunscrever à educação amazônica na historiografia e pesquisa nacional principalmente por falta de espaço em se possa encontrar dados tratados, identificados, organizados, catalogados, sistematizados e disponibilizados à sociedade e pesquisadores e os que se apresentam em educação encontram-se em estado precário; alguns em estado deplorável de deteriorização; os objetivos do estudo; as indicações teóricas preliminarmente reunidas que se aglutinam em torno da discussão da história da educação e da educação na Amazônia, tendo nas fontes históricas do Grupo Escolar padre Luiz Gonzaga, as referências centrais e mais especificamente o processo de articulação, reflexão e discussão sobre à guarda da história e memória da educação; e os encaminhamentos metodológicos.

A perspectiva inicial do estudo, além da preocupação com a preservação dos arquivos e fontes do Grupo Escolar Padre Luiz Gonzaga, para a composição da História da Educação da Amazônia, destinado à pesquisa, à extensão e ensino na História da Educação com vistas à sedimentação da pesquisa em história e da historiografia da educação Amazônica, considera que essa educação, historicamente se pautou na luta para garantia do direito à educação, tendo se constituído em um elemento decisivo de reorganização socioeducacional e que em seu rastro encontram-se vestígios indeléveis das lutas sociais e que, portanto apresentam diversos entendimentos da produção do conhecimento, logo o seu acervo, traz consigo as marcas desse tempo histórico em sua memória.

É bem verdade que as instituições escolares ao longo do tempo, e de acordo com a sociedade na qual se inserem, modificam sua feição. Neste cenário, a história nos permite ver que a escola, em diversos aspectos também tem sofrido transformações, embora pareça manter inalterados alguns de seus elementos. Dessa maneira as instituições se constituem em independentemente de suas origens ou natureza representam uma amostra significativa do que realmente acontece no contexto educacional de um determinado país. Com efeito, as escolas apresentam-se com espaços portadores de fontes de informações fundamentais para a formulação de pesquisas, interpretações e análises sobre elas próprias, as quais permitem compreensão do processo de ensino, da cultura escolar, e consequentemente da História da Educação ${ }^{4}$.

Essa perspectiva de investigação estar para além da ampliação do universo documental, a diversificação do conceito de documento ${ }^{5}$, seja eles, orais ou escritos, implica na valorização e potencialização científica de outros suportes não convencionais encontrado no interior das instituições escolares. 'Os filósofos limitaram - se interpretar o mundo de modos diferentes; o que importa, porém, é transformá-lo (11 Tese sobre Feuerbach). Seguindo o ensinamento de Marx, tornar-se necessário pensar numa possibilidade de mudança a partir da análise do passado por meio das fontes históricas. Atentando para as devidas considerações: 'o que esta instituição singular instituiu? O que ela instituiu para si e para seus sujeitos e para a sociedade na qual está inserida, no caso em questão, a sociedade bragantina,? Mas radicalmente ainda: qual o sentido do que foi instituído6?', pois as instituições escolares são marcas profundas de uma determinada organização social que no Brasil trazem as marcas das de diversas tentativas educacionais.

As instituições escolares geram importantes coleções de documentos e registros educacionais. Contudo, ainda pode-se dizer que esses documentos têm sido pouco utilizados como fonte histórica. Isto significa 
que boa parte dos métodos empregados na pesquisa em educação reconhece pouco valor histórico dos documentos que revelam as "tradições e regularidades institucionais sedimentadas ao longo do tempo ${ }^{7}$.

Para compreender melhor o processo de constituição da Educação da Amazônia faz necessário ampliar conhecimentos sobre a história de sua produção. Essa tarefa demanda organização, catalogação das fontes históricas sobretudo as escritas e outros materiais referentes aos diversos processos, porque ainda que as pesquisas realizadas apontem um legado, as fontes históricas ${ }^{8}$ encontram-se dispersas, fragmentadas e sob a guarda de diferentes pessoas, cujo acesso é muito restrito e em muitos casos deterioradas.

Por outro lado, a questão da falta de tratamento ao estudo local, regional e nacional $^{9}$ da História da Educação constitui-se num problemática educacional em todo Brasil, sobretudo quando a questão é remetida aos Cursos de Licenciaturas.

[...] nos cursos de pedagogia e licenciaturas, em geral, pouco se discutiu ou discute-se sobre o valor histórico do documento e as suas concepções. Se os diretores, secretários de educação, professores, alunos, etc., em larga medida, apenas manuseiam o documento como recurso momentâneo e não tem conhecimento da importância da organização e da guarda dessas fontes para o estudo da história da educação, como desenvolver um processo de valorização da memória educacional? Mesmo nos cursos de pós-graduação ou em outros cursos de formação acadêmica é pouco discutida a necessidade do uso do recurso heurística, ou seja, da busca do documento como recurso essencial para o estudo da história da educação ${ }^{10}$.

Apesar das dificuldades, incursões à História da Educação da Amazônia, apontadas nos relatórios de pesquisas, dissertações e teses, indicam que essa história constitui-se em pedaços de pedaços da história da educação brasileira. História que revela exigências dos períodos históricos, a movimentação das forças sociais que compuseram a sociedade, a partir de seus interesses, de suas condições materiais e opções políticoideológicas, produziram debates intensos numa tentativa de orientar os rumos das políticas sociais, incluindo as do ensino.

A produção do conhecimento na área da História da Educação, na Amazônia revela-se singular e em seu processo de construção foi demonstrando um número considerável de fontes históricas indicando aos pesquisadores caminhos que devem ser trilhados em busca de outros referencias de construção do conhecimento "dito" amazônico. Um deles, sem dúvidas, referem-se ao, o tratamento dado as fontes que ainda é pequeno, como é o caso dos grupos escolares paraenses que estão por ser pesquisados e muitos deles, encontram em estado de conservação lastimável, exigindo restauração imediata.

No caminho da pesquisa em História da Educação na Amazônia, a última década, procura acompanhar a perspectiva sobre o papel da História da Educação, colocando-a no âmbito da produção de novos conhecimentos, consoante ao debate nacional.

O processo de discussão alcançado pela ciência da História, pouco a pouco foi sendo apropriado pela História da Educação e a área foi instaurando questões complexas e singulares sobre o seu objeto - a educação e o seu "alargamento objetual", bem como, um importante debate sobre o método, o recorte espacial e o exercício da heurística para encontrar as fontes, possibilitando uma revisão vigorosa sobre a historiografia da educação brasileira $^{11}$. 
Em se tratando dos acervos das instituições escolares amazônicas, tendo por base, os grupos escolares paraenses ${ }^{12}$, constatamos que uma boa parte foi extraviada, em alguns casos por falta de cuidados com seus prédios, a exemplo do Grupo Escolar Monsenhor Mâncio Ribeiro, em Bragança - PA, construído em lugar de um cemitério para ajudar a elevar o ensino, servindo por muito tempo a população bragantina, educando e profissionalizando. Atualmente encontra-se em um total abandono. (http://mqrosario.blogspot.com.br/p/projeto-patrimonio-historico.html. Acesso em 30 abril, às 16:30h).

No dizer do professor e Historiador Rodrigues (2010).

Sua estrutura atual está carecendo de cuidados especiais urgentes, devido o estado de conservação do prédio. Como historiador e como professor, não posso me resguardar de tecer comentários acerca da demora em agir e dos desencontros de órgãos do Governo do Estado (Secretarias de Estado de Educação e de Cultura) no que se refere à recuperação e restauração completa do imóvel ${ }^{13}$.

Parece que tais instituições já cumpriram com seu papel e hoje podem ser "descartadas". A história de seu legado educacional, pouco interessa; adentrar em seus porões, só quem tem coragem e ousadia e se suas fontes históricas que guardam boa parte do legado educacional do estado do Pará, se não recebem a tempo o cuidado devido, correm um sério risco de perda, alienação e dispersão.

Considerando a fala do professor Sanfelice (2010, p. 4) que ao se manifestar sobre essa questão indica.

As instituições escolares têm também uma origem quase sempre muito peculiar. Os motivos pelos quais uma unidade escolar passa a existir são os mais diferenciados. Às vezes a unidade escolar surge como uma decorrência da política educacional em prática. Mas nem sempre. Em outras situações a unidade escolar somente se viabiliza pela conquista de movimentos sociais mobilizados, ou pela iniciativa de grupos confeccionais ou de empresários. A origem de cada instituição escolar, quando decifrada, costuma nos oferecer várias surpresas.

E considerando também que com a ampliação e consolidação do campo da História da Educação, cada vez mais no cenário científico e que o uso de fontes históricas assume importância. 'Dentre os vários pontos discutidos, o uso das fontes é, sem dúvida, um dos mais importantes e sempre requer atenção especial. Pode-se afirmar que, sem fontes, dificilmente seria possível atribuir o status científico às pesquisas que objetivam ser de História da Educação'(Hermenegildo, 2010, p.7).

As análises sobre Fontes históricas do Grupo Escolar Padre Luiz Gonzaga, ajudam a compor e a consolidar o processo de estudo em instituições escolares, método e fontes da História da Educação da Amazônia, no século XX. 


\section{Grupo Escolar Padre Luiz Gonzaga: método, arquivos e fontes da História da Educação da Amazônia, no século XX.}

O Grupo Escolar Padre Luiz Gonzaga, fundado em 19 de março de 1964, localizado no município de Bragança-PA, Avenida Nazeazeno Ferreira S/N, no Bairro Padre Luiz Freire, há mais de 50 anos "educando gerações para transformação social"14.

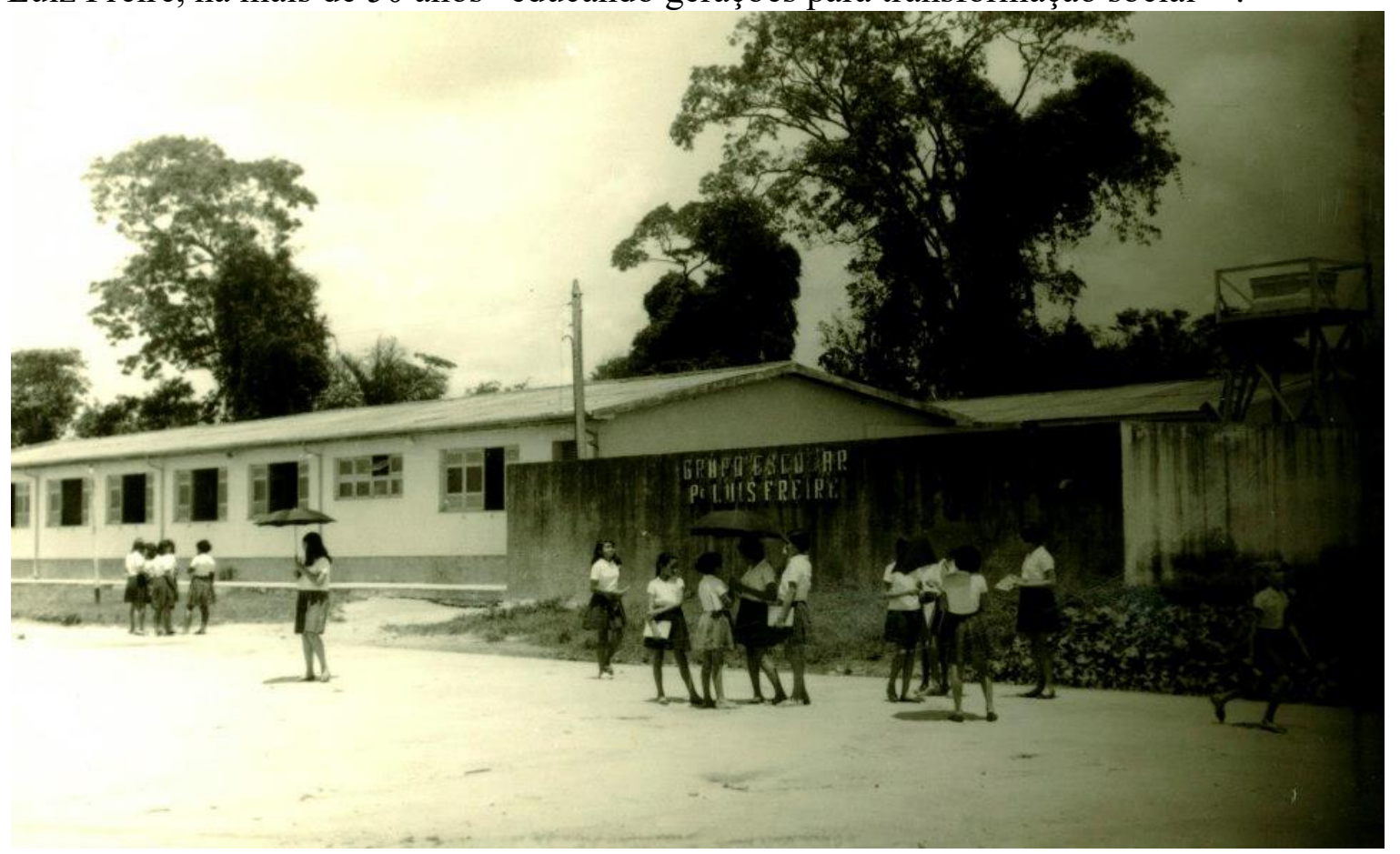

Retrato - Acervo Museu da Educação - HISTEDBR-Secção-PA.

O Grupo, é uma das instituições escolares mais antigas de Bragança e no bairro e por muitos anos, por ser a única, cuidou da formação de crianças, jovens e adultos dos bairros da redondeza, como Perpétuo do Socorro, Boca da Estrada, Aviação, etc.

Para se chegar às fontes, a equipe fez todo um trabalho de articulação envolvendo professoras, diretora e secretária antigas, das décadas de 1960 e 1970 e diretora e professoras que atualmente trabalham no Grupo. Inicialmente a intenção era só trabalhar com as fontes históricas escritas, entretanto após as primeiras incursões percebeu-se que era impossível dado a quase ausência da documentação mais antiga, já que parte de sua documentação, perdeu-se em seus porões (banheiros).

Desse modo, optou-se por recorrer-se a fontes orais como mais uma ferramenta para se chegar ao objetivo, pois a memória do Grupo encontra-se na lembrança daquelas (es) que fizeram e fazem parte da instituição e também porque há um consenso entre os pesquisadores de que o trabalho com fontes orais ampliou-se no sentido de valorizar todos aqueles que estejam representados nas pesquisas e investigações, valorizando vozes de pessoas, trajetórias de vida, memórias, biografias, histórias que possam dar respostas aos questionamentos, sobre um determinado fenômeno. (SARAT e SANTOS, 2010)

Com propósito de reocupação e análise de sua história, o HISTEDBRSecção-PA., e o GEPHE por meio do projeto Museu da Educação Amazônico, se lançaram na aventura de investigá-lo. Ao todo formam ouvidas, em momentos diferentes, 09 professoras, uma secretaria e uma diretora. Dos encontros a equipe sempre saia com fotografias e informações preciosas e reveladoras sobre o funcionamento do Grupo. '[...] A entrevista propiciará, também, um meio de descobrir documentos escritos e fotografias que, 
de outro modo, não teriam sido localizados. (THOPSON, 1992, p. 25). Ao mesmo tempo foi se montando uma rede de informantes que se revelou auspiciosa no sentido de nos ajudar a contar uma parte da história das instituições escolares, por meio do grupo, bem como forneceu material em que se pode discutir fontes à história da educação Amazônica.

As fontes indicam o grupo, segundo a diretora ouvida, como importante instrumento de articulação da proposta de expansão da educação primária nos anos de 1960. Criado em 1962, inicialmente funcionou em uma casa alugada ${ }^{15}$, pintada de rosa bebê a qual foi adaptada para a função de escolarização. Eram 09 salas de aula, uma sala administrativa onde funcionava secretária e diretoria, atendia mais ou menos 300 alunos, de $1^{\text {a }}$ a $4^{\text {a }}$ séries, do ensino primário, em 4 turnos (matutino, intermediário, vespertino e noturno).

Análise ao processo de educação do período, indicam que esse tipo de instituição escolar, atendia a reivindicação da nova população da cidade, ou seja, os agricultores e pescadores dos campos de cima e de baixo ${ }^{16}$, das praias e colônias ${ }^{17}$, foram empurrados para os arrabaldes e lá chegando, exigiam do governo municipal, escolas para seus filhos. São marcas da década de 1960, que atravessada por situações de ordem políticas, econômicas, ideológicas, culturais e sociais deixaram em seu processo histórico em nosso país, e em grande parte da América do Sul, o que é o controle social exercido pelas forças dominantes.

Nesse período, Paulo Freire 'interpretava a sociedade brasileira dos anos de 1960 como processo de trânsito de uma sociedade fechada para uma sociedade aberta' (SAVIANI, 2008). Nesse sentido, 'os setores esquecidos do campo - verdadeiros órfãos da política populista- começaram a se mobilizar. O pano de fundo dessa mobilização parece se encontrar nas grandes mudanças estruturais ocorridas no Brasil entre 1950 e 1964, caracterizadas pelo crescimento urbano' (BÓRIS, 2002).

Além disso, o País passava por um processo tenso de renúncia mudança do modelo político em que o novo presidente realizava alianças e reestruturação na máquina governamental com a finalidade de garantir-se no poder.

Na primeira reunião de todo ministério, quase um mês após a posse, em 28 de fevereiro - o presidencialismo havia sido restabelecido pela Emenda Constitucional $n^{\circ}$ 6, de 23 de janeiro -, Jango anunciou a decisão de levar a cabo uma política de austeridade para o saneamento das finanças, o que significaria romper com a inércia administrativa do período parlamentarista. A situação não era nada confortável. (VILLA, 2004, p.99 $)^{18}$

Se for verdade, que 'as instituições escolares se constituem em independentemente de suas origens ou natureza representam uma amostra significativa do que realmente acontece no contexto educacional de um determinado país', o Grupo Escolar Padre Luiz Gonzaga, no contexto bragantino, era uma amostra da educação. 


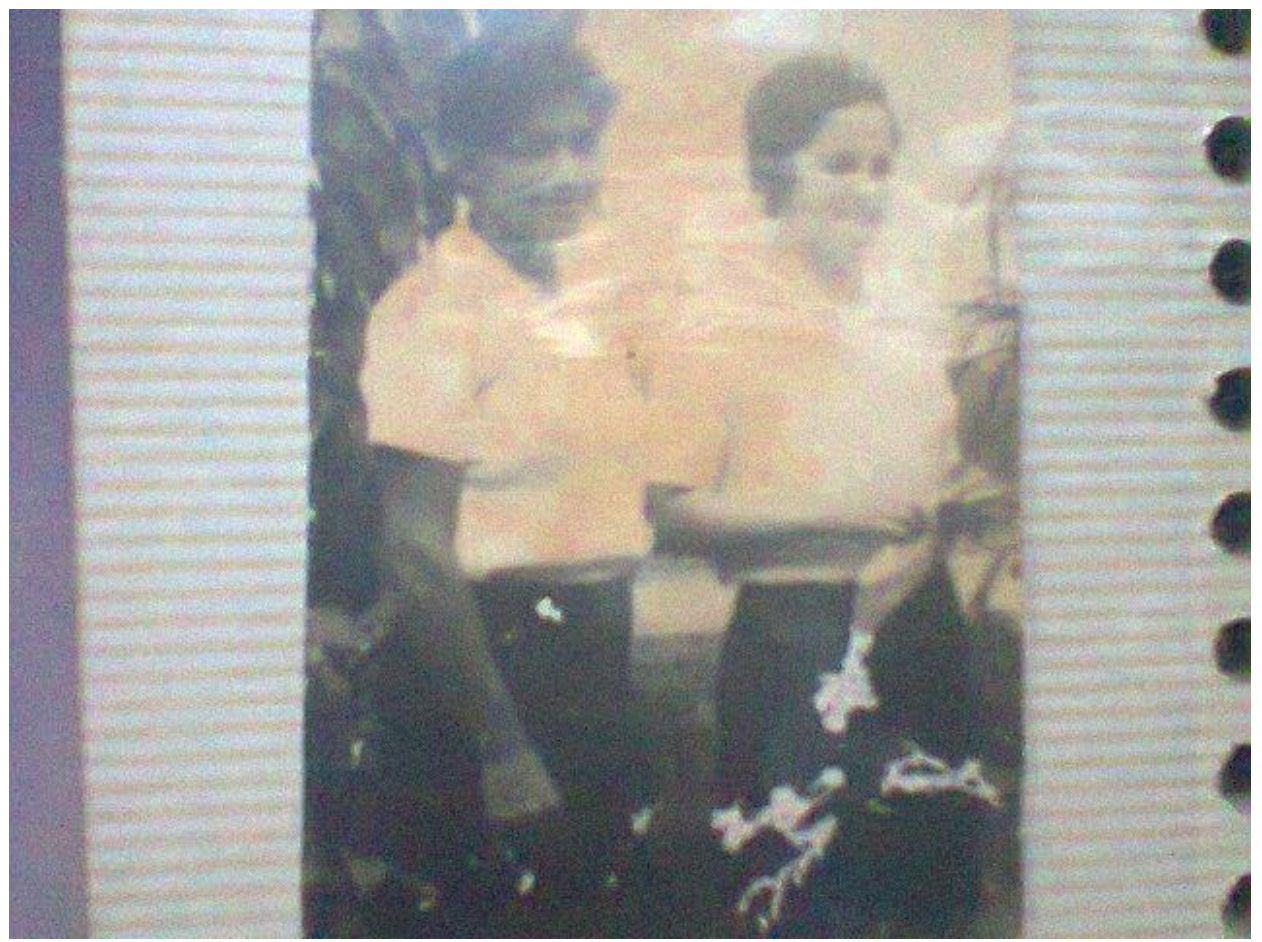

Retrato da Diretora e Professora nos anos 1970, cedida pela diretora e hoje sob a guarda do acervo do HISTEDBR/GEPHE.

Nos anos de 1970, o grupo fora transferido para nova construção, realizada governo do estado - SEDUC. O prédio constava com 06 salas de aula, dependência administrativa, banheiros, pátio coberto e área livre.

Neste seu espaço de atuação, o grupo também era tido como modelo pedagógico, segundo depoimentos de professoras, secretária e segunda diretora.

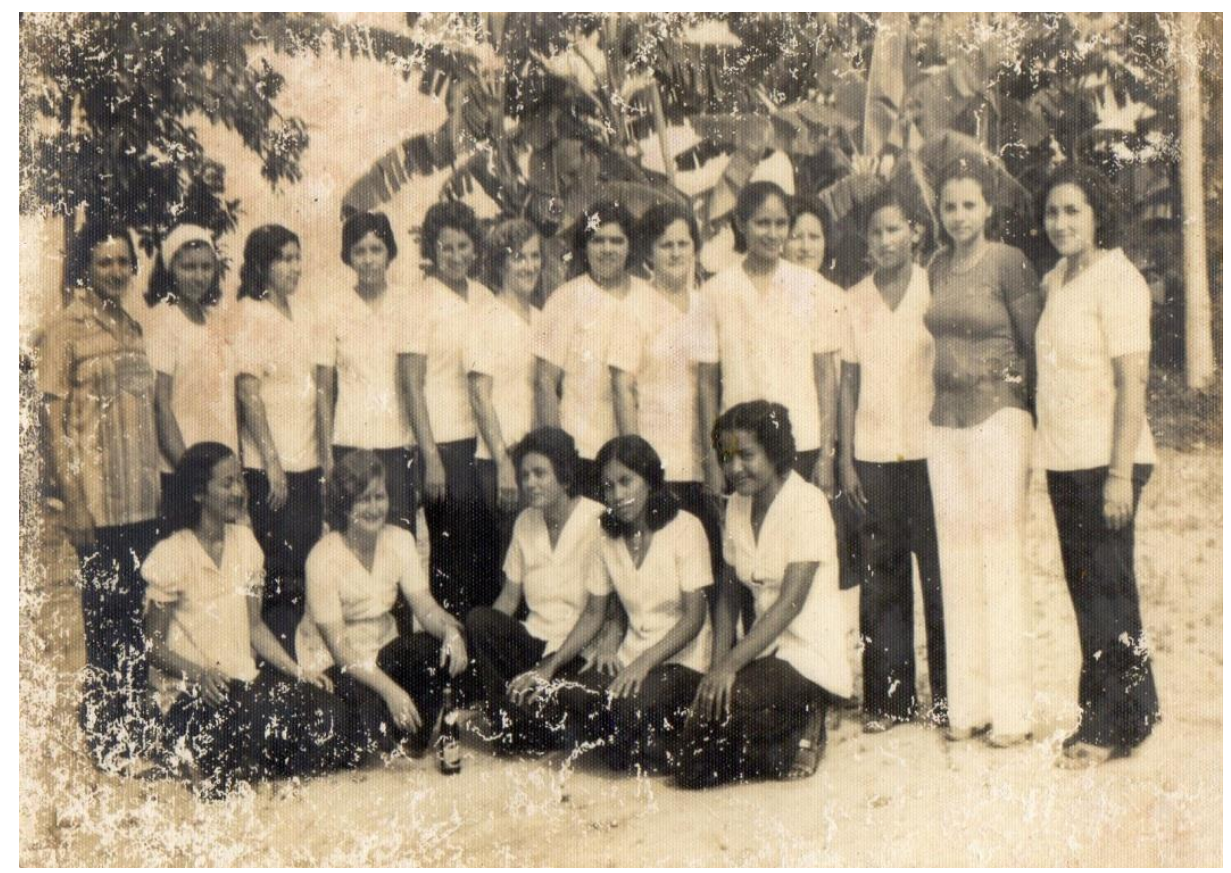

Retrato de 1978. Acervo - Museu da Educação - HISTEDBR - Secção-PA. 
Como era comum, o grupo contava em seu quadro de professoras leigas, haja vista que as contratações obedeciam às necessidades e as indicações da primeira URE.

Minha contratação foi para Bacuriteua, porém a professora Ana Souza de Oliveira, a pedido da diretora do Grupo, mandou -me com a professora de Inglês para começar minha vida de professora por lá. Sem experiência, cursando o $2^{\circ}$ ano normal fui lotada em uma turma de alfabetização juntamente com outra professora leiga. Passei 02 anos e depois assumir a turma sozinha, passando 08 anos. (Fala de professora, em 2014)

A diretora, a secretária e as professoras ouvidas destacam pontos importantes e fortes de educação.

a) $\mathrm{O}$ respeito e a disciplina às crianças e adolescentes, "todos tinham respeito por nós, às regras eram aceitas de bom grado, o horário era cumprido. Não é como hoje, alunos sem limites, intolerantes a qualquer tipo de regra social", relata uma professora.

Esse entendimento pode ser derivado da emergência da concepção produtiva em educação que 'adquiriu força impositiva ao ser incorporada a legislação na forma dos princípios da racionalidade, eficiência e produtividade [...]' (SAVIANI, 2008);

b) o amor à pátria mostrado por meio do cântico do Hino Nacional, 'naquela época todo mundo sabia cantar o hino nacional, hoje se perdeu o respeito, por este símbolo da pátria', ressalta a secretária; além dos hinos do Pará e de Bragança. A demonstração era reforçada, no dizer de uma professora, nos desfiles de 7 de setembro, 'era ferrenho, com banda marcial, atuação ótima, os ensaios eram acompanhados por um instrutor do Tiro de Guerra e no dia 7 o grupo todo uniformizado com saia pregueada azul marinho, blusa, de tergal branca, com um bolso do lado esquerdo, sapatos pretos e meias pretas.' Outra professora arremata, 'os desfiles eram muito voltados para pátria, para nosso estado isso e as autoridades iam junto como prefeito'.

Outra professora diz, "não esqueço o desenho do bolso da blusa. Fecho os olhos e vejo-o. Sou capaz de desenha - lo. O uniforme do grupo era muito vistoso e conhecido em toda Bragança. Abaixo desenho feito pela professora.

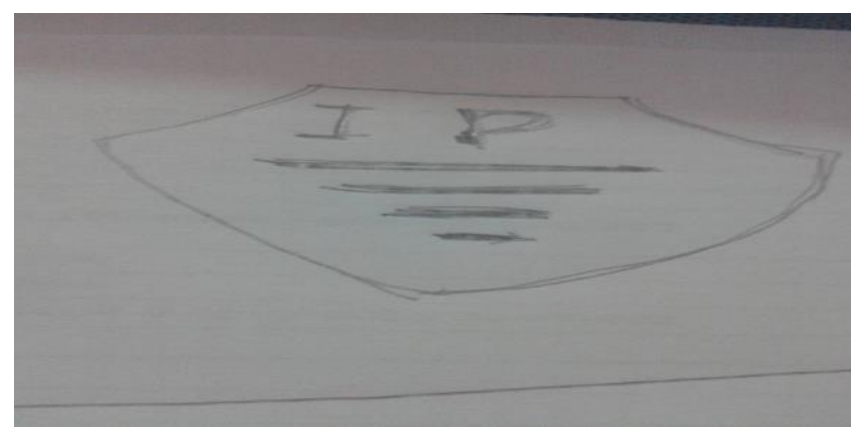

Imagem do bolso da camisa dos estudantes, os traços representam as séries.

c) acesso ao ensino, 'não deixava nenhuma criança sem estudar, dizia: professora coloque mais um em sua sala', orgulha - se a diretora. 'Porém quando em 1971, a superlotação alcançou todos os limites, foi necessário procurar alternativas, desse modo, foi feita uma negociação com escola Escola Cenecista Professor Paixão e os alunos da $5^{\text {a }}$ série foram transferidos para lá, sem prejuízo do ano letivo', diz a secretária. 
d) influência da igreja católica. A catequese, do grupo, era de responsabilidade da paróquia que por intermédio de um sacerdote, preparava, em mais ou menos 6 meses, os alunos nos ritos da igreja, tendo como ápice a realização da primeira comunhão, onde pelos retratos, observa-se a divisão de classe, os pobres de uniforme e no final da fila e os "ricos" vestidos a rigor e perfilavam-se no início. Além dessa preparação, outra professora destaca que "o grupo era "obrigado a participar de duas outras atividades religiosas, festividade de Nossa Senhora do Perpétuo do Socorro e Corphus Christis. À época era tirada uma comissão com alunos maiores de $3^{\mathrm{a}}$ e $4^{\mathrm{a}}$ série (sabiam se comportar melhor) para encaminhar os trabalhos' e representar o grupo na Paróquia.'

d) a merenda escolar, composta de leite e mingau de fubá que inicialmente era proveniente da Cáritas Brasileira e distribuído aos alunos e mais tarde por doações de pessoas do bairro, também denominado de Padre Luiz. Na lembrança de uma professora 'ainda me lembro como se fosse hoje dos sacos (papel) de leite que chegavam, haviam atravessado oceanos para alimentar crianças de todo Brasil. As que estudavam no grupo adoravam'.

e) as comemorações "culturais", nas lembranças das professoras, eram importantes e de grande relevância. No dizer de uma professora.

As comemorações eram encargos das professoras de cada sala. Comemorava-se o dia índio, das mães, do soldado, da árvore, ocasiões em que se discutiam as questões relacionadas com cada temática e sua relevância. A escola toda participava. Com destaque para festas juninas com suas danças, fogueiras e desfile de misses. A população do bairro comparecia em peso, nos prestigiava, pois acreditava no nosso trabalho.

f) indumentária das professoras, blusa branca e saia preta. 'Era bonito de ver as professoras do Padre Luiz, com seus uniformes e orgulhosas da profissão, nós nos encontrávamos, na rua para irmos à escola, morávamos quase todas no arredores da escola, quadras A, B, C e D'. O uniforme era conhecido em Bragança'. diz uma professora.

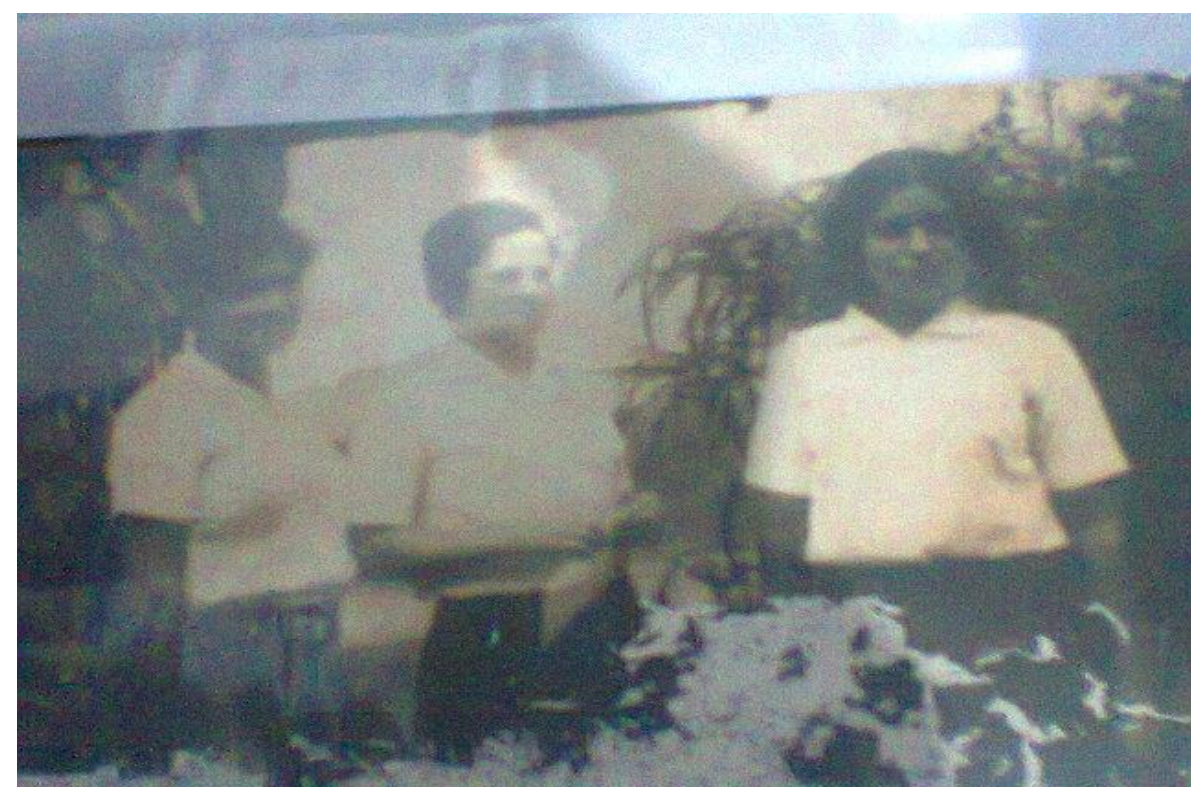

Retrato cedido pela diretora ouvida, cópia acervo HISTEDBR-Secção-PA. 
A análise preliminar, permite afirmar, no grupo escolar Padre luiz Gonzaga vestígios de uma educação que acompanhou as mudanças ocorridas na sociedade brasileira e bragantina, às vezes sem se dar conta e outras nem sempre. 'passamos do ensino velho (referindo-se ao ensino primário e secundário) para o ensino novo (ensino de primeiro grau e segundo grau, quando da instituição da lei 5.692/71), sem muitos traumas, foi tudo normal, como mandava a Secretaria de Estado de Educação do Estado do Pará - SEDUC, por meio do Seu Landolfo Alves (espécie de secretário de educação)', afirma a secretária.

A fala parece não considerar que o grupo, a exemplo de outras instituições escolares brasileira, no período da ditadura, promoveu uma transição, entre os estudos promovidos sob a égide da lei 4.024/61 e a lei 5.692/71, que promovera a reforma de ensino de $1^{\circ}$ e $2^{\circ}$ grau, no país.

O golpe militar de 1964 exigiu adequações no campo educacional efetivadas mediante mudanças na legislação do ensino. Em decorrência, a lei n. 5.692/71, modificou os ensinos primário e médio, alterando sua denominação respectivamente para primeiro grau e segundo grau. Nessa nova estrutura, desapareceram as Escolas Normais. Em seu lugar foi instituída a habilitação específica de $2^{\circ}$ grau para o exercício do magistério de $1^{\circ}$ grau (HEM). Pelo parecer n. 349/72 (Brasil-MEC-CFE, 1972), aprovado em 6 de abril de 1972, a habilitação específica do magistério foi organizada em duas modalidades básicas: uma com a duração de três anos (2.200 horas), que habilitaria a lecionar até a $4^{\mathrm{a}}$ série; e outra com a duração de quatro anos (2.900 horas), habilitando ao magistério até a $6^{\mathrm{a}}$ série do $1^{\mathrm{o}}$ grau. (SAVIANI, 2009, p 13-14).

Em seu quadro de quadro de professoras, até 1982, ainda que nem todo formado em ensino normal ou habilitação magistério, no dizer de uma professora ' quase todas nós éramos formadas pelo Instituto Santa Teresinha, escola particular católica, com tradição na formação de professoras, ou seja, tínhamos uma boa formação. Acho que só uma não era'. Neste caso, o grupo tinha em seu quadro a figura da professora leiga, já que a lei 5.692/71 exigia para as primeiras séries iniciais do ensino fundamental, a habilitação magistério.

Finalizando, as fontes históricas analisadas permitem dizer, o grupo escolar Padre Luiz Gonzaga, criado no final dos anos de 1960, para atender uma demanda da população originaria do campo e que no seu espaço de atuação contou com forte influência da Igreja Católica mantendo uma tradição de participação em festas religiosas, desfiles escolares, festas alusivas à datas importantes, uniformes e distribuição de merenda. Pelo orgulho que suas professoras, diretora e secretaria falam, pode-se afirmar, o Grupo Escolar Padre Luiz Gonzaga, é uma das instituições escolares mais importantes de formação do povo bragantino, no Século XX, e, por conseguinte, da Amazônia. Acreditando nessa possibilidade e a partir desses dados iniciais como elementos significativos, apontamos para a necessidade imperiosa da pesquisa na área de história da Educação. O resgate da história e memória do Grupo, é sem dúvida, um excelente exemplo e um passo importante nessa busca.

\section{Referências}


BITTENCOURT, Ana Pamira. A Pesquisa e a Preservação de Arquivos e Fontes para a Educação, Cultura e Memória. São Paulo - Campinas: Editora Alínea e Átomo, 2009

CHAGAS, Mário de Souza e NASCIMENTO JUNIOR, José do(organizadores).Subsídios para a criação de Museus Municipais Rio de Janeiro, RJ: Ministério da Cultura/Instituto Brasileiro de Museus e Centros Culturais/Departamentode Processos Museais, 2009. 40p.ISBN 978-85-7334-125-6

CENTRO DE PESQUISA E DOCUMENTAÇÃO DA História CONTEMPORÂNEA BRASILEIRA - CPDOC. Guia brasileiro de fontes para a história da África, da escravidão negra e do negro na sociedade atual. Fundação Getúlio Vargas

CENTRO DE PESQUISA E DOCUMENTAÇÃO DA História CONTEMPORÂNEA BRASILEIRA - CPDOC. Guiade acervos bibliográficos e arquivistas de ex-presidentes da República. Fundação Getúlio Vargas

BÓRIS, Fausto. História do Brasil. São Paulo: Editora da Universidade de São Paulo, 2002

FABIANO, Luiz Hermenegildo. MELO, Joaquim José Pereira. Fontes e métodos em História da Educação. Dourado, MS: Ed. UFGO, 2010. 350p.

HISTEDBR. Cartografia das fontes documentais para a história da Educação Maranhense no período imperial. HISTEDBR - Maranhão

LE GOFF.J. História e Memória. Campinas São Paulo: Ed. UNICAMP, 1992.

MAGALHÃES, Lívia Diana R. Museu pedagógico:o professor de catalogação das fontes $\begin{array}{llllll}\text { documentais } & \mathrm{e} & \text { escolares } & \mathrm{em} & \text { Vitória } & \text { da }\end{array}$ Conquista.http://www.histedbr.fae.unicamp.br/navegando/artigos_frames/artigo_058 .html. Acesso em 8/04/11, às 10:00h.

MARX, Karl. Teses sobre Feuerbach, 1845. Disponivel em https://www.marxists.org/portugues/marx/1845/tesfeuer.htm. Acesso em 30 abril, às 1434h.

NUNES, Clarice. Guia preliminar de fontes para a história da educação. Brasília: INEP, 1992.

RODRIGUES, Dário Benedito. Escola Monsenhor Mâncio Ribeiro: um aniversário para comemorar?

http://profdariobenedito.blogspot.com.br/2010/02/escola-estadual-monsenhormancio.html.

ROSÁRIO, Maria José Aviz.A organização da educação no Município de Belém - PA, de 1937 a 1945. Piracicaba-SP: Dissertação (D). Universidade Metodista de Piracicaba UNIMEP, 1998. 
ROSÁRIO, Maria José Aviz. O PCB E A ORGANIZAÇÃo DO ENSINO PÚBLICO PRIMÁRIO DE BELÉM DO PARÁ (1945 a 1964). São Carlos - SP, Tese (T). Universidade Federal de São Carlos - UFSCAR, 2006

SAMARA, Eni de Mesquita. História, documento e metodologia de pesquisa. Belo Horizonte: Autêntica Editora, 2010.

SANFELICE. José Luis.História, instituições escolares e gestores educacionais. Revista HISTEDBR - On line. Número especial. Agosto de 2006. http://www.histedbr.fae.unicamp.br/revista/edicoes/22e/rev22e.html. Acesso em 21/12/12, às 20:49.

SAVIANI, Dermeval. O local e o nacional na historiografia da educação brasileira. São Paulo - Campinas: Editora Alínea, 2008.

SAVIANI, Dermeval. Formação de professores: aspectos históricos e teóricos do problema no contexto brasileiro. Revista Brasileira de Educação v. 14 n. 40 jan./abr. 2009. http://www.scielo.br/pdf/rbedu/v14n40/v14n40a12.pdf. Acesso em 27/02/15, às 13:47h.

TANURI, Leonor Maria. História da formação de professores. Universidade Estadual de São Paulo, 2000. N $\mathrm{N}^{\mathrm{O}}$ 14. http://www.scielo.br/pdf/rbedu/n14/n14a05. Acesso em 27/01/15, às 16:16h.

THOPSON, Paul. A voz do passado: história oral. Rio de Janeiro: Paz e Terra, 1992

VILLA, Marco Antonio. Jango: um perfil (1945 - 2004). São Paulo: Globo, 2004

\footnotetext{
${ }^{1}$ Artigo apresentado, no VII Congresso Brasileiro de História da Educação, realizado, no período de 20 a 23/05/13, na Universidade Federal do Mato Grosso - UFMT - http://gem.ufmt.br/cbhe7/FrmInscricao.aspx. Depois da apresentação outros estudos e investigações foram empreendidas no sentido de se trabalhar e incorpora outras fontes históricas à discussão realizada em 2013. Ao artigo, portanto amplia o debate sobre fontes históricas do Grupo Padre Luiz Gonzaga.

${ }^{2} \mathrm{O}$ projeto de criação do Museu da Educação Amazônico, prevê cinco fases articuladas e que ao mesmo tempo se constituem em sujeito e objeto da história da educação da Amazônia.

${ }^{3}$ O projeto é vinculado ao Grupo de Estudos e Pesquisa, História, Sociedade e Educação no Brasil HISTEDBR - Secção - PA - UFPA - ICED - FAED, pretende transformar o espaço da Sociedade Paraense da Educação em Museu da Educação Amazônico.

${ }^{4}$ FABIANO, Luiz Hermenegildo. MELO, Joaquim José Pereira. Fontes e métodos em História da Educação. Dourado, MS: Ed. UFGO, 2010. 350p.

5 Sobre conceito de documento, consultar: LE GOFF (2000) e SAMARA, Eni de Mesquita. História, documento e metodologia de pesquisa. Belo Horizonte: Autêntica Editora, 2010.

${ }^{6}$ SANFELICE. José Luis. História, instituições escolares e gestores educacionais. Revista HISTEDBR - On line. Número especial. Agosto de 2006. http://www.histedbr.fae.unicamp.br/revista/edicoes/22e/rev22e.html. Acesso em 21/12/12, às 20:49.
} 
${ }^{7}$ MAGALHÃES, Lívia Diana. Museu pedagógico: o professor de catalogação das fontes documentais e escolares em Vitória da Conquista.http://www.histedbr.fae.unicamp.br/navegando/artigos_frames/artigo_058.html. Acesso em 30/03/11, às 19:50h.

${ }^{8}$ De 1951 a 1961, o Executivo Municipal criou mais de 30 escolas. ROSÁRIO (1998).

${ }^{9}$ Sobre essa questão, consultar. LOMBARDI, José Claudinei. ROSÁRIO, Maria José Aviz do Rosário. MELO, Clarice Nascimento de. O Nacional e o Local na História da Educação. Campinas - São Paulo: Editora Átomo e Alínea, 2013

${ }^{10}$ MAGALHÃES, Lívia Diana. Museu pedagógico:o professor de catalogação das fontes documentais e escolares em Vitória da Conquista.http://www.histedbr.fae.unicamp.br/navegando/artigos_frames/artigo_058.html. Acesso em 30/03/11, às 20:14h.

${ }^{11}$ MAGALHÃES, Lívia Diana R. Museu pedagógico:o professor de catalogação das fontes documentais e escolares em Vitória da Conquista.http://www.histedbr.fae.unicamp.br/navegando/artigos_frames/artigo_058.html. Acesso em 20/12/12, às 19:59h0

${ }^{12}$ Em Bragança, os prédios das instituições escolares mais antigas não recebem tratamento adequado, a exemplo do Colégio Cenecista Professor Paixão, transformado em projeto de loja de departamento e grupo escolar Mâncio Ribeiro. http://profdariobenedito.blogspot.com.br/2010/02/escola-estadual-monsenhormancio.html. Acesso em 20/01/13, às 11:17

$13 \mathrm{http}: / /$ profdariobenedito.blogspot.com.br/2010/02/escola-estadual-monsenhor-mancio.html. Acesso em $\underline{20 / 1 / 13}$, as $18: 40 \mathrm{~h}$.

${ }^{14}$ Ver comemoração do jubileu de ouro, no blog: padreluizgonzaga.blogspot.com.br/

${ }^{15}$ A casa foi demolida, em seu lugar foi construída e garagem da empresa de ônibus, Boa Esperança.

${ }^{16} \mathrm{O}$ município de Bragança, á época, contava com dois lugares, campos de cima e campos de baixo, semelhantes ao campos do Arquipélago do Marajó

${ }^{17}$ Atendia ainda as localidades de Bacuriteua, Tamatateua, Pinheiro, Japetá, Ferreira, Urubuquara, Jacareteua, Cariambá, entre outras.

${ }^{18}$ VILLA, Marco Antonio. Jango: um perfil (1945 - 2004). São Paulo: Globo, 2004.

Recebido: mai/15

Aprovado: $\quad$ jun $/ 15$ 